\title{
Possibilities of Dental Age Assessment in Permanent Teeth: A Review
}

\author{
Ines Willershausen, Moritz Försch and Brita Willershausen*
}

Department for Operative Dentistry, University Medical Centre of the Johannes Gutenberg University Mainz, Germany

\begin{abstract}
The developmental stages of the first and second dentition, combined with abrasive wear of the dental hard tissue can be used for age determination in many mammal species and in humans. Concerning dental age determination, one has to distinguish between invasive techniques, which are mainly applied in dead individuals, and non-invasive methods suitable for living individuals. In contrast to in adults, where only few parameters are available for orientation, age determination in children and adolescents is in general fairly easy, and is facilitated by stereotypical biological growth patterns. In the present article, different methods for dental age determination are introduced, with a special focus on the fields of application, and on the limits of age determination. With increasing age, the number of valid and meaningful dental characteristics diminishes, and therefore the accuracy of dental age assessment decreases.
\end{abstract}

Keywords: Permanent dentition; Age assessment; Living and dead individuals

\section{Introduction}

The determination of the chronological age of adolescents and young adults has gained increasing importance, because due to globalization in most of the industrialized nations the number of criminal cases has also significantly increased, and solving them can often be difficult. This development reflects the increase in the number of immigrants into these countries, which inevitably also involves greater numbers of foreign nationals, for whom often a clear documentation of age is not available. In such cases an age determination will be necessary to supplement or check the available pieces of information. The interest in the age determination of living young persons, for whom no birth certificates are available, is not a recent phenomenon but has a long history. For example, in ancient Rome adolescents were considered mature enough to be drafted into military service, as soon as their second molars had fully emerged [1].

Another example for age assessment as an indicator for chronological age is the usage of tooth development in children and adolescents in the United Kingdom in the 19th century [2]. At that time, it was prescribed by the law that children under the age of 7 years were not punishable for any crimes they had committed. Since at that time modern birth certificates did not yet exist, it was often very difficult to determine the exact age of the children; therefore, this protected them from possible punishment.

For casualty identification various invasive and non-invasive techniques, among them medical, radiological and dental, can be employed. Medical investigations are mainly based on the physical examination of the individual (e.g. BMI, signs of sexual maturity), while radiographs are valuable tools for the determination of epiphyseal plate union in long bones, ossification of skull sutures and others skeletal features [3].

An important aspect of forensic odontostomatology is the age determination of an individual based on dental parameters. There are various reasons why dental structures are considered for age assessment, with some of them highlighted and elaborated on below.

When looking at tooth composition and structure, the dental hard tissue, which is mainly composed of inorganic components, is the most resistant structure of the human body [4]. Often, the teeth of an individual are the sole identifiable structures in a completely destroyed human body. Furthermore, the odontogenesis is known to proceed independently from external influences (e.g major general diseases) [1], and dental structures are subject to a uniform and consistent development, which implies that the so-called "dental age" can be used for age assessment. By the age of 20 years, growth and dental development are complete, and thus become less important, while the physiological changes of use predominate. Therefore, beyond this age, an assessment of age, which is solely based on dental age, has to be judged less reliable [5].

Numerous techniques for dental age assessment based on oral and facial structures have been introduced. In general, a distinction is made between invasive and non-invasive methods. For the age determination in living persons, mainly non-invasive techniques are employed. Invasive methods, such as tooth extractions (e.g. required for the determination of aspartic acid racemization from dentin) cannot be used in living subjects for ethical reasons. In contrast, the taking of $\mathrm{x}$-rays is a non-invasive method, which can be employed in both living and dead individuals.

The different methods applied for dental age assessment include the evaluation of tooth morphology [6-8], morphology of the primary and permanent dentition [9], the degree of skeletal ossification [10] and the analysis of biochemical modifications within the dental hard tissues [11]. Of course, these different techniques differ with respect to their possible field of application and their accuracy.

The above-mentioned techniques, combined with knowledge derived from population studies allow the determination of an individual's biological age. It has to be considered that biological age (or the age of development) should not be equated with chronological age. However, because in most cases the discrepancies between

*Corresponding author: Brita Willershausen, Department for Operative Dentistry, University Medical Centre of the Johannes Gutenberg University Mainz, Augustusplatz 2, D-55131 Mainz, Germany, E-mail: willersh@uni-mainz.de

Received November 11, 2011; Accepted January 16, 2012; Published January 19, 2012

Citation: Willershausen I, Försch M, Willershausen B (2012) Possibilities of Dental Age Assessment in Permanent Teeth: A Review. Dentistry S1:001. doi:10.4172/2161-1122.S1-001

Copyright: (C) 2012 Willershausen I, et al. This is an open-access article distributed under the terms of the Creative Commons Attribution License, which permits unrestricted use, distribution, and reproduction in any medium, provided the original author and source are credited. 
chronological and biological age are only marginal, the biological age represents the true age with good approximation $[3,12]$.

\section{Methods of Dental Age Assessment}

\section{Non-invasive methods}

Age assessment using the Schour and Massler method: In 1941 Schour [13] introduced a chart depicting dental development, derived from the clinical status of 25 patients. In 1988 Kahl [14] updated these findings based on the analysis of 993 panoramic radiographs. In addition, they introduced gender-specific charts of the development of the dentitions. These data still represent the gold standard for modern age determination. However, authors such as Hagg and Rozkovcova $[15,16]$ pointed out that age assessment, which is exclusively based on erupted teeth, is not sufficiently accurate, due to individual variations and external factors interfering with tooth eruption.

Age assessment using the Gustafson and Koch approach: In 1974 Gustafson [17] introduced a new method for age estimation on the basis of dental development. In addition to eruption times they used histological and radiographic findings (such as stage of calcification). However, some authors remarked that the method of Gustafson [17] is only accurate in male patients and therefore rather restricted in its field of application [18].

Age assessment using the third molar development: Many different methods using the development of the "dentes sapientes" have been introduced [18-20]. Radiological examinations such as intraoral radiography, panoramic tomography or cone-beam computed tomography are widely used. These $\mathrm{x}$-ray techniques used in numerous studies on age determination allowed the assessment of the size of the pulp or changes in the diameter and length of the roots.

It has to be pointed out that after complete eruption and occlusal integration of the second molars, only radiological analyses of the development of the third molar can be used for dental age assessment in adolescents $(<24$ years of age).

The studies of Kullmann and Demirjian [21,22], illustrate the investigation of third molar development on the basis of panoramic radiographs. The authors looked at either root development and/or degree of mineralization of the third molars. These techniques were modified by Mincer [20] and served as the basis for studies by Maber, Garn and Olze [23-25], who also looked at third molar development in different ethnic groups and populations.

Bagherpour et al. [26] assessed the dental age development stages in 301 Iranian children aged 6-13 years. In order to classify the children's age according to Demirjian [22], the developmental stages of the left mandibular teeth were examined by means of panoramic radiography. In this study the Demirjian [22] method proved to be particularly suitable for children aged 9-13 years. In younger children an overestimation of the children's biological age was frequently observed, with deviating values of 0.34 years in boys and 0.25 years in girls.

In the study of Blenkin and Evans [27] a total of 3261 children, aged between 1 and 23 years, were investigated. The children were recruited from the patient collective of public dental clinics in the Sydney region. Orthopanthomographs were analyzed and the lower right quadrant was assessed and rated according to Demirjian [22] and the Schour \&
Massler method [13]. The simple maturity Score, which is a modified score according to Demirjian [28] was also employed. The evaluation of the age determination showed that the established method according to Demirjian [22], overestimates the chronological age of the Australian children younger than of 14 years with a mean value of 1 year. The modified Demirjian [28] method was more accurate for children aged between 13-14 years, however this did not apply for children younger than 13 .

It has to be considered that in the study conducted by Demirjian [28] a population French-Canadian child was investigated and that these values can only be transferred to other ethnicities with certain limitations.

In a study by Willershausen [29], the third molar developmental stages of European young adults and adolescents of different ethnical backgrounds were assessed radiologically. The authors aimed at establishing a correlation between third molar root development and chronological age. The assessment of radiographs was performed according to the method of Kullmann [21]. A total of 1202 orthopantomograms from young adults aged between 15 and 24 years were analyzed. Radiographs in which more than one third of the molars were missing were excluded from this analysis. The study was able to prove that the growth pattern of third molars correlates with chronological age. When assessing the age of an individual, the standard error was 2-4 years. In general, root development was more advanced in boys when compared with girls of the same age. Regarding the diverse ethnical background of the subjects, no marked differences in dental growth pattern could be shown. While only $2.5 \%$ of the 18-year-olds revealed fully developed third molars in all four quadrants, this percentage sharply increased to $38 \%$ of the 21 -year-old adults. In a similar study design Schattenberg [30], a total of 1277 radiographs from children and young adults aged between 10 and 21 years were evaluated in order to assess third molar development and chronological age. A particular focus was the root development and root/crown length ratio. Again, a correlation between root development and chronological age was evident. The mineralization of the third molars was initiated at an age of 15-16 years and continued constantly. At a mean age of 21 years, root development was terminated in $62 \%$ of the patients. Boys proved to have a more rapid and earlier root growth than girls.

Age assessment using physiological changes of the teeth during the period of use: Non-invasive methods of age assessment in adults focus on the evaluation of physiological traces of use in the permanent dentition. Murphy, Miles and Molnar [31-33] made use of attrition in permanent teeth for dental age assessment. Biedow and Lackovic $[34,35]$ as well as Martin de las Heras [36] examined chromogenic changes of teeth and roots of extracted teeth. Different methods of combination of clinical and radiological findings have been presented by Azrak [37].

\section{Invasive methods of dental age assessment}

Age assessment using the Gustafson method: In 1950 Gustafson introduced a technique for dental age assessment, using six ageassociated parameters, which were applied to thin sections of extracted teeth. To each of the criteria, 0-3 points were given. Using various classifications, he developed a diagram with different point values Gustafson [38]. Among others, Bang [39] found mathematical as well as systematic deficiencies in Gustafson's method [38]. 
Bang [36] studied the degree of root transparency of extracted teeth, and found it to correspond well to the chronological age. Sengupta [40] as well as Mandojana [41] used similar approaches on human skeletal material, derived either from archaeological sites or of recent origin.

Age assessment using quantification of tooth cementum annulation: The root cementum of human teeth is subject to a physiological lamination process. Different layers of various types of root cementum are formed during continuous physiological change. These patterns can be examined employing thin section light microscopy.

Different studies have addressed the application of this technique to human teeth, which was originally commonly used only in biology and veterinarian medicine. Lipsinic [42] as well as Pilloud [43] found inaccuracies of this method, especially in older individuals, whereas for example Charles and Maat [44,45] found a good correlation between cementum layering and chronological age in humans.

Age assessment using the aspartic acid racemization: Stereochemical changes in amino acids from human tissues can be used for age assessment. These methods employ the time-dependent conversion processes between different enantiomers. Different authors found a high correlation between the extent of racemization of specific amino acids and age, especially in dental hard tissue (e.g. dentin) [4648].

\section{Discussion}

Reports from the literature support the general consensus that dental and chronological age show a correlation up to a certain age. While morphological investigations and radiological examinations yield very precise results in children and adolescents, age estimation in adults is often hindered due to chromogenic changes of the teeth and other physiological traces of use, such as attrition, periodontal destruction, apposition of secondary dentin and/or cementum.

Based on the growing demand for age assessment in living individuals and the necessity of age determination in dead subjects, numerous techniques for dental age assessment based on oral and facial structures have been introduced. In general, a distinction is made between, invasive $[49,50]$ and non-invasive methods. Age determination in living persons mainly employs non-invasive techniques. Invasive methods such as tooth extraction (e.g. required for the determination of the degree of aspartic acid racemization in dentin), cannot be used in living subjects for ethical reasons. With advancing age, human beings become increasingly influenced by external factors as well as by their own lifestyle. In consequence, when using morphological parameters for age determination in adults, a high variability and strong deviations from the true biological age can be found. In the literature, discrepancies of many years, sometimes even decades, between assumed and true age have been reported. In a study combining the clinical and radiological dental status of patients, deviations of 14 to 17 years in men, and 12 to 15 years in women to the chronological age were reported [37]. In a study by Olze [51], the combination of the DMFT indices of all permanent teeth, the DMFT indices of the third molars, the eruption time of the third molars and the degree of periodontal destruction around the second molars only yielded correct age values for $69.7 \%$ of the men and $71.4 \%$ of the women. It has been shown that radiological investigations as a non-invasive method for dental age determination can be largely standardized and thus become acceptable as means to achieve meaningful results. The investigation of Kvaal [52] in which dental age assessment was conducted on the basis of single tooth radiographs, showed that satisfactory results could be achieved. The method is based on the fact that with growing age the diameter of the pulp chamber is reduced due to the apposition of secondary dentin, which can be observed and measured on x-rays. However, this method is being discussed controversially in the literature [52-55]. These considerations are based on the fact that numerous external influences such as dietary habits and oral hygiene measures, in connection with the ethnicity of the individuals, have to be regarded as influential parameters in the apposition of secondary dentin [56]. It is well known that the apposition of tertiary dentin, which is formed in reaction to external influences such as caries or an abnormal occlusion, also leads to a reduction in the size the pulp chamber. However, in children and adolescents the dental age assessment based on the development of the wisdom teeth has proven to allow the age assessment of an individual with an accuracy of \pm 2 to 4 years [20,21,29,57,58 ].

When evaluating the dental developmental stages based on the method of Demirjian [22] it has to be considered that these values refer to a specific population sample. As a consequence, the genetic heritage of the investigated patient collective has to be taken into account when utilizing this method. The different cultural backgrounds lead to marked differences in the dental developmental stages, a fact which has been underlined in numerous studies. [59-63]

When assessing the dental age based on the degree of tooth mineralization and eruption, assertions on the biological age are only possible up to 20-21 years of age [64]. For a more precise determination of an individual's true age, additional parameters such as the biological variations within the wisdom teeth development have to be considered. In contrast to the second molar, growth deviations of 4 to 8 years can be found in wisdom teeth [65]. It could be shown that when additional factors, like the number of wisdom teeth present, and supportive diagnostics (such as physical examinations, radiographs of the left hand and the clavicle) were considered, an age determination as precise as \pm 12 months [58] is possible with a probability of $80-90 \%$ [67].

Nevertheless, the dental system has to be seen as an integral part of the whole human body. Development, age and growth have to be evaluated together with other physiological maturity factors, such as skeletal age, onset of menarche, and height according to Demirjian [22].

In conclusion, one can see that the developmental stage of third molars per se is not a highly useful indicator for the assessment of chronological age in juveniles and young adults. Nevertheless, it has to be considered as a valuable supplementary parameter given the scarcity of other available age indicators. When including other diagnostic parameters, a relatively precise assessment of the true biological age is possible. However, there are several factors with can influence dental age assessment in the daily practice (regarding non-invasive methods): High individuality and possible variations between epidemiological findings and the rates of single tooth development of the given individual patient, the clinical experience of the observer in judging sequential stages of the tooth formation and the availability of earlier and later data from the patient as basis for reference.

\section{References}

1. Müller N (1990) Dental age determination based on the assessment of third molar development. Inauguraldissertation, MedizinischeFakultät der Friedrich, Alexander-Universität Erlangen, Nürnberg. 
Citation: Willershausen I, Försch M, Willershausen B (2012) Possibilities of Dental Age Assessment in Permanent Teeth: A Review. Dentistry S1:001. doi:10.4172/2161-1122.S1-001

2. Miles AEW (1963) Dentition in the estimation of age. J Dent Res42: 255-263.

3. Ferembach D, Schwidetzky I, Stloukal M (1979) References for the age and gender diagnosis of the skeleton. Homo 30: 1-32.

4. Endris R (1982) ForensischeKatastrophenmedizin. Kriminalistikverlag Heidelberg.

5. Someda H, Saka H, Matsunaga S, Ide Y, Nakahara K, et al. (2009) Age estimation based on three-dimensional measurement of mandibular central incisors in Japanese. Forensic Sci Int 185: 110-114.

6. Solheim T (1988) Dental attrition as an indicator of age. Gerodontics 4: 299304.

7. Solheim T (1988) Dental color as an indicator of age. Gerodontics 4: 114-118.

8. Solheim T (1989) Dental root translucency as an indicator of age. Scand J Dent Res 97: 189-197.

9. Mörnstad H, Staaf V, Welander U (1994) Age estimation with the aid of tooth development: a new method based on objective measurements. Scand J Dent Res 102: 137-143.

10. Schmeling A, Schulz R, Reisinger W, Mühler M, Wernecke KD, et al. (2004) Studies on the time frame for ossification of the medial clavicular epiphyseal cartilage in conventional radiography. Int J Legal Med 118: 5-8.

11. Ritz S, Schütz HW, Peper C (1993) Postmortem estimation of age at death based on aspartic acid racemization in dentin: its applicability for root dentin. Int J Legal Med 105: 289-293

12. Leopold D (1998) Identification of unknown dead persons. Schmidt-Römhild Lübeck.

13. Schour I, Massler M (1941) The development of the human dentition. J Am Dent Assoc 28: 1153-1160.

14. Kahl B, Schwarze CW (1988) [Updating of the dentition tables of I. Schour and M. Massler of 1941]. Fortschr Kieferorthop 49: 432-443.

15. Hägg U, Matsson L (1985) Dental maturity as an indicator of chronological age: the accuracy and precision of three methods. Eur J Orthod 7: 25-34.

16. Rozkovcová E, Marková M, Mrklas L (2005) Third molar as an age indicator in young individuals. Prague Med Rep 106: 367-398.

17. Gustafson G, Koch G (1974) Age estimation up to 16 years of age based on dental development. Odontol Revy 25: 297-306.

18. Olze A, Schmeling A, Taniguchi M, Maeda H, van Niekerk P, et al. (2004) Forensic age estimation in living subjects: the ethnic factor in wisdom tooth mineralization. Int J Legal Med 118: 170-173.

19. Kullman L, Martinsson T, Zimmerman M, Welander U (1995) Computerized measurements of the lower third molar related to chronologic age in young adults. Acta Odontol Scand 53: 211-216.

20. Mincer HH, Harris EF, Berryman HE (1993) The A.B.F.O. study of third molar development and its use as an estimator of chronological age. J Forensic Sci 38: $379-390$.

21. Kullman L, Johanson G, Akesson L (1992) Root development of the lower third molar and its relation to chronological age. Swed Dent J 16: 161-167.

22. Demirjian A, Goldstein H, Tanner JM (1973) A new system of dental age assessment. Hum Biol 45: 211-227.

23. Maber M, Liversidge HM, Hector MP (2006) Accuracy of age estimation of radiographic methods using developing teeth. Forensic Sci Int 159 Suppl 1: S68-73.

24. Garn SM, Wertheimer F, Sandusky ST, Mc Cann MB (1972) Advanced tooth emergence in Negro individuals. J Dent Res 51: 1506.

25. Olze A, Taniguchi M, Schmeling A, Zhu BL, Yamada Y, et al. (2004) Studies on the chronology of third molar mineralization in a Japanese population. Leg Med (Tokyo) 6: 73-79.

26. Bagherpour A, Imanimoghaddam M, Bagherpour MR, Einolghozati M (2010) Dental age assessment among Iranian children aged 6-13 years using the Demirjian method. Forensic Sci Int 197: 121
27. Blenkin MR, Evans W (2010) Age estimation from the teeth using a modified Demirjian system. J Forensic Sci 55: 1504-1508.

28. Demirjian A, Goldstein H (1976) New systems for dental maturity based on seven and four teeth. Ann Hum Biol 3: 411-421.

29. Willershausen B, Löffler N, Schulze R (2001) Analysis of 1202 orthopantograms to evaluate the potential of forensic age determination based on third molar developmental stages. Eur J Med Res 6: 377-384.

30. Schattenberg A, Ferraraccio A, Pistorius A, Willershausen B (2007) Developmental stages of wisdom teeth for dental age assessment. Dtsch Zahnarztl Z 62: 803-807.

31. Murphy T (1959) The changing pattern of dentine exposure in human tooth attrition. Am J Phys Anthropol 17: 167-178.

32. Miles AE (1962) Assessment of the Ages of a Population of Anglo-Saxons from Their Dentitions. Proc R Soc Med 55: 881-886.

33. Molnar S (1971) Human tooth wear, tooth function and cultural variability. Am $J$ Phys Anthropol 34: 175-189.

34. Biedow J (1963) A modified method for age determination of teeth

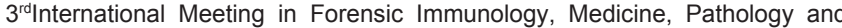
Toxicology, London.

35. Lackovic KP, Wood RE (2000) Tooth root colour as a measure of chronological age. J Forensic Odontostomatol 18: 37-45.

36. Martin-de lasHeras S, Valenzuela A, Bellini R, Salas C, Rubiño M, et al. (2003) Objective measurement of dental color for age estimation by spectroradiometry. Forensic Sci Int 132: 57-62.

37. Azrak B, Victor A, Willershausen B, Pistorius A, Hörr C, et al. (2007) Usefulness of combining clinical and radiological dental findings for a more accurate noninvasive age estimation. J Forensic Sci 52: 146-150.

38. Gustafson G (1950) Age determination on teeth. J Am Dent Assoc 41: 45-54.

39. Bang G, Ramm E (1970) Determination of age in humans from root dentin transparency. Acta Odontol Scand 28: 3-35.

40. Sengupta A, Whittaker DK, Shellis RP (1999) Difficulties in estimating age using root dentine translucency in human teeth of varying antiquity. Arch Oral Biol 44: 889-899.

41. Mandojana JM, Martin-de las Heras S, Valenzuela A, Valenzuela M, Luna JD (2001) Differences in morphological age-related dental changes depending on postmortem interval. J Forensic Sci 46: 889-892.

42. Lipsinic FE, Paunovich E, Houston GD, Robison SF (1986) Correlation of age and incremental lines in the cementum of human teeth. J Forensic Sci 31: 982 989.

43. Pilloud S (2004) Can there be age determination on the basis of the dental cementum also in older individuals as a significant context between histological and real age determination. Anthropologischer Anzeiger 62: 231-239.

44. Charles DK, Condon K, Cheverud JM, Buikstra JE (1986) Cementum annulation and age determination in Homo sapiens. I. Tooth variability and observer error Am J Phys Anthropol 71: 311-320.

45. Maat GJ, Gerretsen RR, Aarents MJ (2006) Improving the visibility of tooth cementum annulations by adjustment of the cutting angle of microscopic sections. Forensic Sci Int 159 Suppl 1: S95-S99.

46. Helfman PM, Bada JL (1975) Aspartic acid racemization in tooth enamel from living humans. Proc Natl Acad Sci U S A 72: 2891-2894.

47. Bada JL, Helfman PM (1975) Amino acid racemization dating of fossil bones World Archaeol 7: 160-173.

48. Ohtani S, Yamamoto K (1987) Age estimation using the racemization of aspartic acid on human dentin. Nihon Hoigaku Zasshi 41: 181-190.

49. Ohtani S, Yamamoto K (1991) Age estimation using the racemization of amino acid in human dentin. J Forensic Sci 36: 792-800.

50. Saleh N, Deutsch D, Gil-Av E (1993) Racemization of aspartic acid in the extracellular matrix proteins of primary and secondary dentin. Calcif Tissue Int 53: $103-110$ 
Citation: Willershausen I, Försch M, Willershausen B (2012) Possibilities of Dental Age Assessment in Permanent Teeth: A Review. Dentistry S1:001. doi:10.4172/2161-1122.S1-001

51. Olze A, Mahlow A, Schmidt S, Wernecke KD, Geserick G, et al. (2005) Combined determination of selected radiological and morphological variables relevant for dental age estimation of young adults. Homo 56: 133-140.

52. Kvaal S, Solheim T (1994) A non-destructive dental method for age estimation. J Forensic Odontostomatol 12: 6-11.

53. Meinl A, Tangl S, Pernicka E, Fenes C, Watzek G (2007) On the applicability of secondary dentin formation to radiological age estimation in young adults. $J$ Forensic Sci 52: 438-441.

54. Prapanpoch S, Dove SB, Cottone JA (1992) Morphometric analysis of the dental pulp chamber as a method of age determination in humans. Am J Forensic Med Pathol 13: 50-55.

55. Schroeder HE, Krey G, Preisig E (1990) Age-related changes of the pulpal dentin wall in human front teeth. Schweiz Monatsschr Zahnmed 100: 14501461.

56. Philippas GG (1961) Influence of occlusal wear and age on formation of dentin and size of pulp chamber. J Dent Res 40: 1186-1198.

57. Loitz C (1992) Determination of the developmental stages of wisdom teeth as a means for age determination. Dissertation. Fachbereich Medizin der Universität Hamburg.

58. Nortjé CJ (1983) The permanent mandibular third molar. Its value in age determination. J Forensic Odontostomatol 1: 27-31.

59. Davis PJ, Hägg U (1994) The accuracy and precision of the "Demirjian system" when used for age determination in Chinese children. Swed Dent J 18: 113116 .
60. Mörnstad H, Reventlid M, Teivens A (1995) The validity of four methods for age determination by teeth in Swedish children: a multicentre study. Swed Dent $J$ 19: $121-130$.

61. Liversidge HM, Molleson TI (1999) Developing permanent tooth lengths as an estimate of age. J Forensic Sci 44: 917-920.

62. Davidson LE, Rodd HD (2001) Interrelationship between dental age and chronological age in Somali children. Community Dent Health 18: 27-30.

63. Eid RM, Simi R, Friggi MN, Fisberg M (2002) Assessment of dental maturity of Brazilian children aged 6 to 14 years using Demirjian's method. Int J Paediatr Dent 12: 423-428.

64. Gunst K, Mesotten K, Carbonez A, Willems G (2003) Third molar root development in relation to chronological age: a large sample sized retrospective study. Forensic Sci Int 136: 52-57.

65. Haavikko K (1970) The formation and the alveolar and clinical eruption of the permanent teeth. An orthopantomographic study. Suom Hammaslaak Toim 66: 103-170.

66. Schmeling A, Olze A, Reisinger W, König M, Geserick G (2003) Statistical analysis and verification of forensic age estimation of living persons in the Institute of Legal Medicine of the Berlin University Hospital Charité. Leg Med (Tokyo) 5 Suppl 1: S367-S371.

67. Friedrich RE, Ulbricht C, von Maydell LA (2003) Orthopantomographs of young adults and adolescents as a means for forensic age determination. Relationship between the chronological age and the number of missing teeth. Rechtsmedizin 13: 137-146. 